\title{
The impact of labor mobility on industrial upgrading in China
}

\author{
Li ShaSha ${ }^{1}$ \\ ${ }^{1}$ School of Economics and Management, Beijing Jiaotong University, Beijing 100044, China
}

\begin{abstract}
Using the data of 2010 population census and $20151 \%$ population sample survey in China and the data published by the National Bureau of Statistics, the index of industrial structure transformation was adopted to measure the explained variable of industrial upgrading, and the least squares model was constructed to investigate the impact of migrant labor force on industrial upgrading and its influencing mechanism. Research shows that the migrant labor force has a positive impact on the transformation of industrial structure, and increasing the proportion of urban migrant labor force is conducive to promoting the transformation of agricultural economic structure into non-agricultural industries. Furthermore, the paper discusses the mechanism through which labor flow affects industrial upgrading, and the test results show that labor flow promotes urban industrial upgrading through local market effect and human capital accumulation mechanism. Labor flow is a process of improving the efficiency of resource allocation. Cities attract a large number of foreign labor, which is of great significance to the transformation and upgrading of urban industrial structure.
\end{abstract}

\section{Introduction}

For decades since reform and opening up, economic growth has been accompanied by massive population migration in China. Migrant labor force has become an important part of urban labor market and has gradually become the main supply source of new labor force. The migration of rural labor force to cities has provided a key support for China's economic growth [1]. In the era of dual economy, China has made full use of its population structure and quantity advantages, gained the competitive advantage of labor-intensive industries, and occupied the position of the world's manufacturing industry in the global industrial division of labor. Sustained economic growth in China is an important reason of the department of agriculture's marginal productivity relative to the industry, manufacturing industry is low, a large number of rural labor force transferring to non-agricultural sectors improved the allocation efficiency of the economy, on the other hand the Labour is cheap, at the same time of saving cost greatly promotes the total factor productivity [2]. However, in recent years, with the accelerating aging of China's population age structure, rising labor costs and the gradual loss of "demographic dividend", it is difficult to maintain the development relying on the factor input of the traditional economic and industrial structure development model. In order to enhance the global competitiveness of economic industries and achieve sustained growth, China's economy must upgrade and optimize its industrial structure [3]. As the carrier of labor as an important factor of production, the change of its flow and supply will directly affect the pace of industrial structure transformation and upgrading. In the context of accelerating the transformation of China's population and economic structure, it is of great academic value and practical significance to discuss the influence of labor mobility on industrial upgrading and the internal mechanism of action.

\section{Literature review}

As for how labor mobility affects industrial upgrading, existing studies mainly focus on the impact of trade factors [4], industrial policies [5], educational investment [6], capital factors and geographical environment on industrial upgrading [7]. Rostow leading industry diffusion theory shows that leading industry drives the demand of a series of related industries through forward, backward and side effects, so as to promote the expansion and upgrading of the industry. Before the emergence of the Internet, industrial development and upgrading were mainly driven by producer demand and consumer demand. Therefore, demand is an important driving force of industrial upgrading. Considering production input according to demand, from the perspective of input factors, not only physical capital is the key factor of industrial structure, but also the accumulation and innovation of human capital is the key factor affecting industrial upgrading. Economic growth depends on the progress of technology and scientific knowledge, while the development of science and technology depends on the accumulation of human capital, so human capital investment and economic growth are closely related. The higher the concentration of human capital, the better the productivity. With the continuous fairness and fairness of social division of labor and the reduction of transaction costs, knowledge and human capital will make industries develop from labor-intensive 
to capital-and technology-intensive through innovation, thus promoting regional industrial upgrading and economic growth. Previous empirical analysis shows that although capital accumulation plays a key role in terms of output, the quality and quantity of labor directly affect the growth of economic output. Therefore, labor force plays a crucial role in industrial upgrading, and the rapid development and convenience of transportation make labor force constantly flowing, which will also have a certain impact on industrial structure. More attention should be paid to the influence of human capital and migrant labor force in the study of factors affecting industrial upgrading.

However, the research of scholars does not directly explain the relationship between labor mobility and industrial upgrading. As a direct carrier of consumer demand and human capital, labor mobility is bound to be related to the economic development and industrial structure adjustment of a region. Since the neoclassical economic theory regards labor force as an exogenous hypothesis, few scholars have directly linked labor flow and industrial upgrading. Existing literature mainly focuses on the impact of trade, industrial policy, demand, material capital input, human capital concentration, innovation and geographical environment on industrial upgrading, but lacks in-depth research on the impact of labor flow on industrial upgrading and the mechanism of action.

\section{Data and model}

The population and labor data in this paper are derived from the national population census in 2010, and microscopic data from the sample survey of $1 \%$ of the population in 2015. Migrant labor force is defined as the labor force who has lived or worked in this city for more than half a year and whose household registration is not in this city.

The explanatory variables are the proportion of foreign labor force, and the explanatory variables are the proportion of non-agricultural industry, the proportion of secondary industry and the proportion of tertiary industry. Based on previous studies on factors affecting industrial upgrading, the control variables in this paper are set as population density, natural growth rate of population, utilization of foreign capital, fixed asset investment, market size, working age, time of flow, region and other relevant variables.

This paper establishes an econometric model to verify the industrial upgrading effect of labor mobility, and sets the following benchmark regression model for this purpose:

$$
Y_{i, t}=\beta_{0}+\beta_{1} m r_{i, t}+\beta_{2} X_{i, t}+\delta_{i, t}
$$

Where Y stands for industrial upgrading, i for region and $\mathrm{T}$ for time. $\mathrm{mr}_{\mathrm{i}, \mathrm{t}}$ represents the proportion of migrant labor force in urban labor market, which is the core explanatory variable of this paper and is defined as the proportion of migrant labor force in the total labor force of this city. $\delta_{\mathrm{i}, \mathrm{t}}$ is the residual term of the equation. In order to reduce the deviation of omitted variables, $\mathrm{X}_{\mathrm{i}, \mathrm{t}}$ is set as the control variable of urban economy.

In order to test the mechanism of the effect of the entry of foreign labor on the industrial upgrading, this paper will build an econometric model to further observe whether the labor flow has an impact on the level of urban human capital and local market demand. Therefore, the following regression model is set up:

$$
M_{i, t}=\gamma_{0}+\gamma_{1} m r_{i, t}+\gamma_{2} K_{i, t}+\varepsilon_{i, t}
$$

Where, $M_{i, t}$ is the explained variable, $i$ is the region, $t$ is the time. $\mathrm{mr}_{\mathrm{i}, \mathrm{t}}$ represents the migration ratio of migrant labor force, which has the same meaning as above. $\varepsilon_{\mathrm{i}, \mathrm{t}}$ is the residual term of the equation. In order to reduce the deviation of omitted variables, $\mathrm{K}_{\mathrm{i}, \mathrm{t}}$ is set as the control variable of urban economy. Among them, the selection of explained variables is divided into three parts. In this paper, the index of total retail sales of social goods is used to represent the local market effect, the average education level of urban population is used to measure the level of urban human capital, and the annual proportion of urban financial investment in education and scientific research is used to measure the intensity of investment in urban scientific research and innovation.

\section{Empirical analysis}

As shown in Table 1, on the whole, migration has a significant positive impact on industrial upgrading indicators. The regression coefficient is 0.098 , which passes the $1 \%$ significance level test, indicating that migration has a positive impact on the development of nonagricultural industries. It can be seen from model (2) that the action coefficient of migration is 0.011 , but it is not significant, indicating that the increase of migration ratio does not have a significant impact on the output value ratio of the secondary industry. It can be seen from model (3) that the regression coefficient of migration is 0.151 , which passes the significance level test of $1 \%$, which means that the increase of the migration ratio will lead to the increase of the output value ratio of the tertiary industry. The above results show that the increase in the proportion of migrant labor force will promote the transfer of industrial structure to non-agricultural industries, and in non-agricultural industries, the labor force flow plays a more significant role in promoting the tertiary industry than the secondary industry. The above regression results are also consistent with the reality. From 2000 to 2015 , the development trend of urban industrial employment structure and output value structure is as follows: the proportion of the primary industry and the secondary industry generally shows a trend of fluctuation and decline, while the proportion of the tertiary industry gradually rises, which also conforms to the general law of industrial upgrading. This means that more and more people will be employed in the tertiary industry, and the probability of migrant workers to work in the tertiary industry is also increasing. There is an interactive relationship between labor mobility and the tertiary industry, that is, while the tertiary industry absorbs migrant labor, labor mobility also plays a positive role in promoting the development of the tertiary industry.

The above analysis shows that labor mobility has a significant positive impact on industrial upgrading. Then through what mechanism does labor flow exert an effect on industrial upgrading?The underlying mechanism of action 
will be further explored in the following paragraphs.

For a city, under the condition of regional trade costs relatively unchanged, human capital accumulation into the higher areas will attract a large number of labor force, to help expand consumption market of the city, through the local market effect, can attract into the production of high value-added products manufacturers, at the same time will have certain extrusion effect on low value-added industries, the labor productivity of the whole industry will get promoted, to help industrial upgrading. At the same time, labor mobility will also change the allocation of regional human capital, and highly skilled labor will form agglomeration. On the one hand, it forms a competitive labor market, which to a large extent ensures the vitality and efficiency of the labor market and improves the allocation efficiency of labor factors. On the other hand, local industries benefit from the spillover effect of human capital and technological innovation, improve labor productivity from the micro level, and realize industrial upgrading. Empirical verification will be carried out below.
According to the regression results in The fourth column of Table 1, labor mobility has a positive impact on the scale of local market. The regression coefficient is 1.165 . Through the significance level test of $1 \%$, it shows that the increase of migration ratio is conducive to the expansion of the scale of local market demand, and the local market effect mechanism of migration on industrial upgrading exists. On the one hand, after migrant labor enters the city, in the long run, it can cause enterprises to expand the scale of investment and stimulate the investment demand. After the fruits of economic growth are distributed in a wider range, it will stimulate the consumption demand and expand the local market demand. On the other hand, migrant labor force is not only the supplier of labor factors, but also one of the main sources of urban consumer demand. The inflow of labor force into cities will directly expand the urban consumer market and give better play to the local market effect of cities.

Table1. The impact of migration on industrial upgrading and mechanism analysis

\begin{tabular}{|c|c|c|c|c|c|c|}
\hline & \multicolumn{3}{|c|}{ Regression results } & \multicolumn{3}{|c|}{ Influence mechanism } \\
\hline & (1) & (2) & (3) & (4) & (5) & (6) \\
\hline The migration & $\begin{array}{c}0.098^{* * * *} \\
(6.59)\end{array}$ & $\begin{array}{c}0.011 \\
(0.22)\end{array}$ & $\begin{array}{c}0.151 * * * \\
(7.67)\end{array}$ & $\begin{array}{c}1.165^{* * *} \\
(7.85)\end{array}$ & $\begin{array}{c}3.434 * * * \\
(7.63)\end{array}$ & $\begin{array}{c}0.031 * * * \\
(5.04)\end{array}$ \\
\hline In (density per capita) & $\begin{array}{c}0.032 * * * \\
(10.59)\end{array}$ & $\begin{array}{c}0.029 * * * \\
(5.15)\end{array}$ & $\begin{array}{c}0.006 \\
(1.03)\end{array}$ & $\begin{array}{c}0.152 * * * \\
(6.87)\end{array}$ & $\begin{array}{c}0.052 * * * \\
(3.92)\end{array}$ & $\begin{array}{c}0.001 \\
(0.82)\end{array}$ \\
\hline Natural population growth rate & $\begin{array}{c}-0.002 \\
(-0.99)\end{array}$ & $\begin{array}{c}-0.001 * * \\
(-2.11)\end{array}$ & $\begin{array}{c}0.001 \\
(1.39)\end{array}$ & $\begin{array}{l}-0.003 \\
(-0.64)\end{array}$ & $\begin{array}{c}0.002 \\
(0.23)\end{array}$ & $\begin{array}{c}0.000 \\
(0.98)\end{array}$ \\
\hline In(actual utilization of foreign capital) & $\begin{array}{l}-0.004 \\
(-1.14)\end{array}$ & $\begin{array}{l}-0.004 * \\
(-3.72)\end{array}$ & $\begin{array}{c}0.002 \\
(1.09)\end{array}$ & $\begin{array}{c}0.058^{* * *} \\
(429)\end{array}$ & $\begin{array}{c}-0.045^{* *} \\
(-2.59)\end{array}$ & $\begin{array}{l}0.002 \\
(0.98)\end{array}$ \\
\hline In (Fixed Asset Investment) & $\begin{array}{c}0.019 * * * \\
(5.58)\end{array}$ & $\begin{array}{c}0.063 * * * \\
(7.60)\end{array}$ & $\begin{array}{c}-0.045^{* * *} \\
(-5.44)\end{array}$ & $\begin{array}{c}0.689^{* * *} \\
(11.22)\end{array}$ & $\begin{array}{c}0.265 * * * \\
(5.74)\end{array}$ & $\begin{array}{c}0.001 * * * \\
(3.59)\end{array}$ \\
\hline In (Total retail sales of Social Goods) & $\begin{array}{l}-0.001 \\
(0.53)\end{array}$ & $\begin{array}{c}-0.043 * * * \\
(-4.90)\end{array}$ & $\begin{array}{c}0.041 * * * \\
(5.89)\end{array}$ & & $\begin{array}{l}-0.105^{*} \\
(-1.69)\end{array}$ & $\begin{array}{c}0.002 \\
(1.09)\end{array}$ \\
\hline Average years of education & $\begin{array}{c}0.006 * * * \\
(2.68)\end{array}$ & $\begin{array}{c}-0.013 * * * \\
(-2.54)\end{array}$ & $\begin{array}{c}0.020 * * * \\
(6.38)\end{array}$ & $\begin{array}{c}0.008 \\
(0.59)\end{array}$ & & $\begin{array}{c}-0.003 * * * \\
(-4.60)\end{array}$ \\
\hline The average age & $\begin{array}{c}0.002 * * * \\
(2.98)\end{array}$ & $\begin{array}{c}0.001 \\
(-1.09)\end{array}$ & $\begin{array}{c}0.002 \\
(1.36)\end{array}$ & $\begin{array}{c}0.031 * * * \\
(3.85)\end{array}$ & $\begin{array}{c}0.115 * * * \\
(7.38)\end{array}$ & $\begin{array}{c}0.001 * * * \\
(3.54)\end{array}$ \\
\hline Time trend variable & $\begin{array}{l}-0.002 * \\
(-1.83)\end{array}$ & $\begin{array}{c}-0.041^{* * * *} \\
(-6.89)\end{array}$ & $\begin{array}{c}0.038^{* * *} \\
(8.94)\end{array}$ & $\begin{array}{c}-0.095^{* * *} \\
(-3.74)\end{array}$ & $\begin{array}{c}-0.489 * * * \\
(-9.02)\end{array}$ & $\begin{array}{c}0.003 \\
(1.15)\end{array}$ \\
\hline The central region & $\begin{array}{c}0.020 * * * \\
(2.82)\end{array}$ & $\begin{array}{l}-0.001 \\
(0.85)\end{array}$ & $\begin{array}{l}0.018^{*} \\
(1.69)\end{array}$ & $\begin{array}{l}-0.058 \\
(-1.22)\end{array}$ & $\begin{array}{c}0.431 * * * \\
(6.18)\end{array}$ & $\begin{array}{c}0.005 * * * \\
(4.72)\end{array}$ \\
\hline The eastern region & $\begin{array}{c}0.008 \\
(1.07)\end{array}$ & $\begin{array}{c}0.008 \\
(0.81)\end{array}$ & $\begin{array}{c}0.005 \\
(0.94)\end{array}$ & $\begin{array}{c}0.098^{* *} \\
(2.19)\end{array}$ & $\begin{array}{l}-0.079 \\
(-0.87)\end{array}$ & $\begin{array}{c}0.005 * * * \\
(4.96)\end{array}$ \\
\hline Cons & $\begin{array}{c}0.401 * * * \\
(7.09)\end{array}$ & $\begin{array}{c}0.419 * * * \\
(4.66)\end{array}$ & $\begin{array}{l}-0.027 \\
(-0.19)\end{array}$ & $\begin{array}{c}1.375^{* * *} \\
(3.83)\end{array}$ & $\begin{array}{c}5.102 * * * \\
(8.79)\end{array}$ & $\begin{array}{c}-0.051 * * * \\
(-5.67)\end{array}$ \\
\hline $\mathbf{N}$ & 1015 & 1015 & 1015 & 1125 & 1125 & 1125 \\
\hline $\mathbf{R}^{2}$ & 0.332 & 0.135 & 0.275 & 0.798 & 0.301 & 0.412 \\
\hline $\mathbf{F}$ & 33.785 & 15.413 & 35.382 & 503.856 & 564.329 & 436.384 \\
\hline
\end{tabular}

Notes: the estimated coefficient is the marginal effect; The value in parentheses is the value of T.

$*, * *$ and $* * *$ mean significant at the level of $10 \%, 5 \%$ and $1 \%$, respectively.

The fifth column of table 1 regression results show that the migration have a positive impact on overall urban average education level, coefficient is 3.434 , and passed the $1 \%$ significance level test, this indicates that the migration population increase is not only improved the overall urban human capital level, and the local urban population level also has a promoting effect of human capital, and the latter is significantly higher than the former. The improvement of human capital has a positive impact on industrial upgrading, which means that the mechanism of migration to promote urban industrial upgrading through human capital level also exists.

In addition, this paper further verified the impact of migration on the investment intensity of scientific research and education. The sixth column regression results in Table 1 showed that the regression coefficient of migration was 0.031 , which passed the $1 \%$ significance level test, and the migration ratio had a positive impact on the investment intensity of scientific research and education. 
The financial investment in scientific research and education of a city not only reflects the investment in human capital and innovation, but also reflects the level of education and scientific research innovation of the city, which is an important driving force for industrial development and upgrading and optimization. The inflow of labor leads to economic agglomeration and professional agglomeration improves enterprises' resource allocation efficiency, while the externality of agglomeration leads to knowledge spillover, which will make technological innovation have a positive impact on the upgrading of regional industrial structure. The above results mean that the increase of the proportion of migrant labor force in cities will exert a positive influence on the accumulation of human capital, scientific research and innovation in cities, so as to promote urban industries to climb to hightech and high value-added industries.

\section{Conclusions}

Using the data from the national population census in 2010 and the data from the sample survey of $1 \%$ of the population in 2015 and the data published by the National Bureau of Statistics, this paper analyzes and investigates the impact and internal mechanism of labor migration on urban industrial upgrading in the new era. Studies show that migrant labor has become an important part of urban labor market, labor force in the urban labor market structure has two characteristics: from the point of accept education degree, by the flow of labor education level and the urban local population, even in the flow of labor force in recent years of higher education. From the perspective of age structure, the age of migrant labor force is younger, and the inflow of migrant labor force not only improves the local industrial economy of the city, but also alleviates the aging phenomenon of urban labor force.

The constant flow of labor force has a significant positive impact on regional industrial upgrading, which can promote regional economic industrial upgrading. Labor mobility promotes economic industrial upgrading by influencing regional market effect and changing human capital accumulation. Specific terms, for many cities, from the point of regional market effect, under the condition of trade costs relatively unchanged, the steady accumulation of human capital inflows help city to attract a large number of high-quality labor force, thus urban consumer market will get the corresponding expansion, will expand the regional market effect, high value-added products will see effect to choose to enter the market, manufacturers will be squeezed out, and low value-added industries and industrial structure change. From the perspective of regional human capital allocation, labor mobility will gather highly skilled labor, and local industries will benefit from the spillover effect of human capital technology, so as to improve productivity and promote the change of industrial structure for upgrading.

China faces an ageing population, a low fertility rate and a shortage of urban Labour. Therefore, in the special period of urban economic structural transformation, labor mobility will not only solve the crisis of urban labor market shortage, but also help to improve the production efficiency of Chinese industries. Furthermore, labor mobility promotes industrial transformation to high valueadded industries and leads to industrial upgrading and optimization. It provides new impetus for economic restructuring and economic growth. On the other hand, it helps to improve the economic living standard and development opportunity of rural labor force. Therefore, from the perspective of long-term urban development, the urban government should take measures to promote the flow of labor force as soon as possible, create favorable conditions to promote the welfare of floating population and attract a large number of high-quality labor force. And further increase investment to improve the level of human capital accumulation in cities, and promote the continuous transformation of China's economy and industries to highquality development.

\section{ACKNOWLEDGMENT}

Thanks to my tutor Yu Linyue from Beijing Jiaotong University for her guidance in research design and discussion.

\section{References}

1. Xiong $\mathrm{S}, \mathrm{Ma} \mathrm{X}$, Ji J . The impact of industrial structure efficiency on provincial industrial energy efficiency in China[J]. Journal of Cleaner Production, 2019, 215:952-962.

2. Wolfgang, Dauth, Jens, et al. Globalization and local profiles of economic growth and industrial change[J]. J Econ Geogr, 2016,16: 1007-1034.

3. Canfei H, Shengjun Z . Economic Transition and Industrial Restructuring in China: Structural Convergence or Divergence?[J]. Post-Communist Economies, 2007, 19(3):317-342.

4. Liu J , Hu X, Wu J . Fiscal decentralization, financial efficiency and upgrading the industrial structure: an empirical analysis of a spatial heterogeneity model[J]. Journal of Applied Stats, 2017, 44(1-4):181-196.

5. $\mathrm{Hu} \mathrm{F}$, Zhao $\mathrm{S}$, Bing $\mathrm{T}$, et al. Hierarchy in industrial structure: The cases of China and the USA[J]. Physica A Statal Mechanics \& Its Applications, 2016:871-882.

6. Xie H, Yang M, Li F . An Empirical Study on the Correlation between Educational Input and Upgrading of Industrial Structure under the Background of Beijing-Tianjin-Hebei Coordinated Development $[\mathrm{J}]$. Educational ences: Theory and Practice, 2018, 18(5).

7. Yung, Chaurshin, Hsu, Mingju. Industrial Upgrading Through Innovation of Technological and Vocational Education[J]. Radiology, 2006, 137(2):343-8. 